\title{
DESEMPENHO DO ABACAXIZEIRO 'VITÓRIA' EM RESPOSTA À APLICAÇÃO DE ÁCIDOS HÚMICOS DURANTE A ACLIMATAÇÃO(1)
}

\author{
Lílian Estrela Borges Baldotto ${ }^{(2)}$, Marihus Altoé Baldotto ${ }^{(3)}$, \\ Validoro Bazoni Giro $^{(4)}$, Luciano Pasqualoto Canellas ${ }^{(3)}$, Fábio \\ Lopes Olivares $^{(5)} \&$ Ricardo Bressan-Smith ${ }^{(6)}$
}

\begin{abstract}
RESUMO
A aclimatação de mudas de abacaxizeiro propagadas por cultura in vitro é um processo lento. A promoção do crescimento radicular pelo uso de ácidos húmicos pode ser útil durante esse processo. O objetivo deste trabalho foi avaliar o desempenho do abacaxizeiro 'Vitória' propagado por cultura de tecidos em resposta à aplicação de diferentes doses de ácidos húmicos isolados de vermicomposto e de torta de filtro durante o período de aclimatação em casa de vegetação. Foram avaliadas as características anatômicas da lâmina foliar, o teor de pigmentos fotossintéticos, o crescimento da parte aérea e do sistema radicular, e o conteúdo de nutrientes foliares. Os resultados mostraram incrementos no crescimento e desenvolvimento da parte aérea e do sistema radicular com a aplicação de ácidos húmicos, bem como acúmulo significativo de $\mathrm{N}, \mathrm{P}, \mathrm{K}, \mathrm{Ca}$ e $\mathrm{Mg}$ e aumento na relação clorofila a/clorofila $b$. A promoção do crescimento das mudas durante o período de aclimatação, em resposta à aplicação de ácidos húmicos, pode melhorar a adaptação do abacaxizeiro ao ambiente ex vitro.
\end{abstract}

Termos de indexação: Ananas comosus, cultura de tecidos, substâncias húmicas, nutrição mineral, bioatividade.

\footnotetext{
(1) Parte da Tese de Doutorado da primeira autora. Recebido para publicação em dezembro de 2008 e aprovado em maio de 2009.

(2) Doutoranda do Programa de Pós-Graduação em Genética e Melhoramento de Plantas da Universidade Estadual do Norte Fluminense Darcy Ribeiro - UENF. Av. Alberto Lamego 2000, CEP 28013-602 Campos dos Goytacazes (RJ). E-mail: liborges@uenf.br

(3) Professor do Laboratório de Solos, UENF. E-mails: marihus@uenf.br; canellas@uenf.br

(4) Bolsista de Iniciação Científica do Laboratório de Solos, UENF. E-mail:validoroagro2009@yahoo.com.br

(5) Professor do Laboratório de Biologia Celular e Tecidual, UENF. E-mail: fabioliv@uenf.br

${ }^{(6)}$ Professor do Laboratório de Fisiologia Vegetal, UENF. E-mail: bressan@uenf.br
} 


\title{
SUMMARY: PERFORMANCE OF 'VITÓRIA'PINEAPPLE IN RESPONSE TO HUMIC ACID APPLICATION DURING ACCLIMATIZATION
}

\begin{abstract}
The acclimatization of pineapple plantlets propagated by plant tissue culture is slow. The intensification of root growth by the use of humic acids may be useful during this process. The aim of this study was to evaluate the greenhouse acclimatization of 'Vitoria' pineapple propagated by plant tissue culture in response to different doses of humic acids isolated from vermicompost and filter cake. Leaf anatomy, photosynthetic pigment content, shoot and root growth, and leaf nutrients were evaluated. An increase in growth and development of shoots and root system with the application of humic acids as well as a significant accumulation of $N$, $P, K, C a$, and $M g$ and increase in the chlorophyll a / chlorophyll b ratio were found. Growth promotion by the application of humic acids to plantlets during the period of acclimatization can improve their adaptation to the ex vitro environmental conditions.
\end{abstract}

Index terms: Ananas comosus, tissue culture, humic substances, mineral nutrition, bioactivity.

\section{INTRODUÇÃO}

A propagação do abacaxizeiro por cultura in vitro é uma estratégia utilizada para elevar a qualidade e produtividade da cultura de abacaxi, devido, entre outros fatores, à uniformidade e sanidade das mudas. A produção in vitro de mudas de abacaxizeiro já está bem estabelecida (Guerra et al., 1999; Teixeira et al., 2001; Almeida et al., 2002; Barboza et al., 2004). Depois de as plantas atingirem desenvolvimento adequado in vitro (Teixeira et al., 2001), elas são aclimatadas em condições ex vitro para posterior adaptação às condições de campo.

O período de aclimatação é necessário, pois plantas cultivadas in vitro apresentam características anatômicas e fisiológicas desfavoráveis para enfrentar as condições edafoclimáticas do campo, como metabolismo heterotrófico (Campostrini \& Otoni, 1996; Moreira, 2001), menor espessamento da cutícula e das paredes periclinais externas das células epidérmicas, e menor densidade estomática (Barboza et al., 2006). A redução da umidade do ar e da disponibilidade de nutrientes durante a aclimatação tende a tornar-se componente limitante para o abacaxizeiro, aumentando sua susceptibilidade a variações ambientais drásticas, mesmo favorecido pelo mecanismo fotossintético ácido inerente às crassuláceas.

Os longos períodos exigidos de aclimatação para o abacaxizeiro oneram a sua produção in vitro. Para exemplificar, é necessário um período variável entre seis e oito meses em casa de vegetação para que as plantas alcancem entre 20 e $30 \mathrm{~cm}$ de altura, tamanho adequado para a transferência para o campo (Teixeira et al., 2001).

Diversos estudos têm sido realizados objetivando diminuir o período de aclimatação do abacaxizeiro com a finalidade de acelerar o crescimento da planta, como aplicação foliar de macro e micronutrientes (Moreira et al., 2007; Bregonci et al., 2008), aplicação de reguladores de crescimento (Catunda et al., 2008), inoculação de bactérias promotoras de crescimento e proteção vegetal (Mello et al., 2002; Weber et al., 2003), tipos de recipientes usados no enraizamento (Souza Júnior et al., 2001; Bregonci et al., 2008) e de substratos (Souza Júnior et al., 2001; Weber et al., 2003; Moreira et al., 2006; Catunda et al., 2008).

Em relação ao substrato, a adição de matéria orgânica favorece o crescimento da parte aérea e do sistema radicular do abacaxizeiro durante a aclimatação (Moreira et al., 2006). Por sua vez, a matéria orgânica é constituída por produtos da decomposição de resíduos orgânicos e do metabolismo microbiano e também por substâncias húmicas (Guerra et al., 2008). Notadamente, as substâncias húmicas constituem a maior parte da matéria orgânica dos solos e são compostas por huminas, ácidos fúlvicos e ácidos húmicos (Guerra et al., 2008). Os ácidos húmicos $(\mathrm{AH})$, formados por agregados moleculares heterogêneos e estabilizados por pontes de hidrogênio e interações hidrofóbicas (Piccolo, 2001), favorecem o desenvolvimento do sistema radicular (Façanha et al., 2002; Rodda et al., 2006; Zandonadi et al., 2007), o acúmulo de nutrientes (Vaughan \& Malcolm, 1985; Chen \& Avaid, 1990; Chen et al., 2004) e a biossíntese de clorofilas (Ferrara \& Brunetti, 2008). Para culturas como arroz (Tejada \& Gonzalez, 2004), trigo (Delfine et al., 2005) e videira (Ferrara \& Brunetti, 2008), tem sido relatada a promoção de crescimento pela aplicação foliar de AH. Em abacaxizeiro, o uso de $\mathrm{AH}$ poderia ser uma estratégia viável na aclimatação de plantas propagadas in vitro, pois poderia promover maior crescimento, resultando em redução no longo tempo necessário para a transferência das plantas para o cultivo em campo.

O objetivo desse trabalho foi avaliar, durante o processo de aclimatação, o crescimento da planta, as características anatômicas da lâmina foliar e o teor de pigmentos fotossintéticos, bem como o acúmulo de nutrientes foliares do abacaxizeiro 'Vitória' propagado 
in vitro, em resposta à aplicação de diferentes doses de ácidos húmicos, isolados de vermicomposto e de torta de filtro.

\section{MATERIAL E MÉTODOS}

\section{Material vegetal}

Plântulas de abacaxizeiro (Ananas comosus L. Merril) do cultivar "Vitória" (INCAPER, 2006) propagadas in vitro, em potes de vidro tipo baby food, foram fornecidas pelo Laboratório de Biotecnologia BioMudas e mantidas em meio MS descrito por Murashige \& Skoog (1962), sem adição de reguladores de crescimento e vitaminas. As plântulas in vitro foram mantidas em sala de crescimento, com fluxo de fótons fotossintéticos de $25 \mu \mathrm{mol} \mathrm{m}{ }^{-2} \mathrm{~s}^{-1}$, temperatura de $25 \pm 2{ }^{\circ} \mathrm{C}$ e fotoperíodo de $16 \mathrm{~h}$. A cada três meses, as plântulas foram transferidas para novo meio, em tubos de ensaio. Para a realização das etapas experimentais posteriores, foram selecionadas mudas com aproximadamente $1,5 \mathrm{~g}$ de matéria fresca.

\section{Tratamentos}

A matriz experimental $[(3 \times 2)+1]$ consistiu dos seguintes fatores em estudo: três doses (10, $20 \mathrm{e}$ $40 \mathrm{mmol} \mathrm{L}^{-1}$ de $\mathrm{C}$ ) de ácidos húmicos isolados de vermicomposto (AHv), três doses (10, 20 e $40 \mathrm{mmol} \mathrm{L}^{-1}$ de C) de ácidos húmicos isolados de torta de filtro (AHtf), e controle sem aplicação de ácidos húmicos. Os ácidos húmicos isolados de vermicomposto e os de torta de filtro foram previamente caracterizados por Baldotto et al. (2007) e Busato (2008). As plântulas foram retiradas dos tubos de ensaio, lavadas em água corrente para a limpeza do meio de cultivo, e o sistema radicular e a base da parte aérea dos abacaxizeiros foram imersos nas soluções dos tratamentos por $24 \mathrm{~h}$. Para esse procedimento, as plântulas foram colocadas em potes de vidro tipo baby food, contendo $50 \mathrm{~mL}$ de solução correspondentes aos diferentes tratamentos. Posteriormente, os abacaxizeiros foram transferidos para vasos de $0,5 \mathrm{dm}^{3}$ contendo substrato comercial Plantmax ${ }^{\circledR}$ Hortaliças para serem aclimatados, em casa de vegetação, por um período de 150 dias. A cada 15 dias durante a aclimatação, as plantas receberam $5 \mathrm{~mL}$ de solução dos tratamentos e $5 \mathrm{~mL}$ de solução nutritiva (Hoagland \& Arnon, 1950), aplicadas nas axilas das folhas basais dos abacaxizeiros, usando-se pipeta automática.

A unidade experimental consistiu em uma planta de abacaxi por vaso. O experimento foi realizado no delineamento em blocos ao acaso, com seis repetições, totalizando 42 unidades experimentais.

\section{Análises de crescimento}

Aos 150 dias de aclimatação, as plantas foram coletadas para a mensuração das seguintes variáveis: número de folhas (NF); altura das plantas (ALT), medida pela distância compreendida entre o colo da planta até o ápice foliar usando-se fita métrica; diâmetro do caule (DC), mensurado com paquímetro digital modelo Starret 727; diâmetro da roseta (DR), medida na maior distância linear entre o ápice de folhas opostas, mensurado com fita métrica; matéria fresca da raiz (MFR) e da parte aérea (MFPA); matéria seca da raiz (MSR) e da parte aérea (MSPA), obtidas pela secagem em estufa sob ventilação forçada de ar a $60{ }^{\circ} \mathrm{C}$ por $7 \mathrm{~d}$ e posterior pesagem; área foliar (AF), obtida no medidor de área foliar de bancada modelo LI-3100, LI-COR, USA; área radicular (AR), medida após a digitalização das raízes e posterior análise das imagens no programa Delta-T SCAN Image Analyzer; relação raiz: parte aérea (RPA), obtida pela razão entre a matéria seca da raiz e a matéria seca da parte aérea.

\section{Análises nutricionais}

Após a secagem, as folhas de abacaxizeiro foram moídas em moinho do tipo Wiley acoplado a peneiras de $0,25 \mathrm{~mm}$ (60 mesh). Em seguida, o pó obtido foi submetido à digestão sulfúrica combinada com peróxido de hidrogênio e foram determinados os teores totais de N, P, K, Ca e Mg. Para N, foi utilizado o método de Nessler; o teor de $\mathrm{P}$ foi obtida por espectrofotometria de absorção molecular (colorimetria), após reação com vitamina C e molibdato de amônio, no comprimento de onda de $725 \mathrm{~nm}$; a determinação de $\mathrm{K}$ foi realizada por fotometria de chama e os teores de $\mathrm{Ca}$ e de $\mathrm{Mg}$ foram obtidos por espectrofotometria de absorção atômica. Todas as análises foram realizadas conforme os métodos usuais para a cultura do abacaxizeiro (Ramos et al., 2006). Os conteúdos de N, P, K, Ca e Mg, foram calculados por meio da multiplicação da matéria seca da parte aérea com o teor do nutriente considerado.

\section{Análises anatômicas}

Cortes transversais do terço médio da lâmina foliar da sétima folha completamente expandida (frequentemente a de maior comprimento) foram feitos à mão livre, usando navalha de aço. As lâminas histológicas foram montadas em glicerina com 50 \% água (Purvis et al., 1964). As observações foram realizadas por meio do microscópio ótico Axioplan - Zeiss acoplado a uma câmara fotográfica digital Canon Power Shot A640. A aquisição das imagens foi feita por meio do programa Zoom Browser EX e as medições no programa Image J (Abramoff et al., 2004). Foram mensurados os comprimentos do parênquima aquífero e do parênquima clorofiliano. As lâminas foliares foram prensadas em fita vegetal, com uma gota de acetona $100 \%$, para dissociação da epiderme abaxial, com posterior quantificação do número de estômatos, em uma área de $0,12 \mathrm{~mm}^{2}$, (objetiva de aumento $20 \mathrm{e}$ zoom digital de aumento 1,4) entre os feixes de fibras.

\section{Análises dos pigmentos fotossintéticos}

O teor de clorofila foi estimado por meio da determinação da intensidade de cor verde da sétima folha completamente expandida do abacaxizeiro 
(frequentemente a de maior comprimento), usando-se um medidor portátil de clorofila modelo SPAD-502 (Soil Plant Analysis Development, Minolta, Japão), com três medições por folha.

Posteriormente, três discos foliares de 1,5 cm de diâmetro foram retirados da mesma folha para determinação do teor de pigmentos fotossintéticos (Hiscox \& Israelstam, 1979). Os discos foliares foram imersos em 3,0 mL de dimetilsulfóxido (DMSO) e mantidos no escuro até ficarem translúcidos. As leituras em espectrofotômetro foram feitas nas absorbâncias de 480, 649 e 665 nm (A480, A649 e A665, respectivamente) e os conteúdos dos pigmentos fotossintéticos foram determinados conforme Wellburn (1994):

$$
\begin{aligned}
& {[\text { Clorofila } a]\left(\mu \mathrm{g} \mathrm{mL}^{-1}\right)=12,19 \text { A665 - 3,45 A649 }} \\
& {[\text { Clorofila } b]\left(\mu \mathrm{g} \mathrm{mL}^{-1}\right)=21,99 \text { A649 - 5,32 A665 }}
\end{aligned}
$$

[Carotenoides] $\left(\mu \mathrm{g} \mathrm{mL}^{-1}\right)=(1000 \mathrm{~A} 480-2,14$ Clorofila $a-70,16$ Clorofila $b$ ) /220

\section{Análises estatísticas}

Os resultados foram submetidos à análise de variância, e os efeitos dos tratamentos, para as variáveis qualitativas, foram desdobrados em contrastes médios (Quadro 1), conforme Alvarez V. \& Alvarez (2006). Para os fatores quantitativos, foram ajustadas equações de regressão entre as médias das variáveis estudadas e as doses de $\mathrm{AH}$. A aplicação do teste $\mathrm{F}$ nos desdobramentos dos fatores foi realizada a 5 e $1 \%$. Na análise de regressão, os modelos foram testados quando apresentaram coeficiente de determinação superior a 0,60. As equações de regressão foram utilizadas para a determinação da dose de máxima eficiência física de produção de matéria seca do abacaxizeiro em função das doses de $\mathrm{AH}$.

Quadro 1. Coeficientes dos contrastes estudados para os tratamentos doses de ácidos húmicos e para o controle

\begin{tabular}{ccc}
\hline & \multicolumn{2}{c}{ Coeficiente dos contrastes $^{(2)}$} \\
\cline { 2 - 3 } Tratamento $^{(1)}$ & C1 & C2 \\
\hline & -6 & 0 \\
AHv (10) & +1 & -1 \\
AHv (20) & +1 & -1 \\
AHv (40) & +1 & -1 \\
AHtf (10) & +1 & +1 \\
AHtf (20) & +1 & +1 \\
AHtf (40) & +1 & +1 \\
\hline
\end{tabular}

(1) Tratamentos: (-): controle; $\mathrm{AHv}$ : ácido húmico de vermicomposto AHtf: ácido húmico de torta de filtro; (10), (20) e (40) representam as concentrações de 10, 20 e $40 \mathrm{mmol} \mathrm{L}^{-1}$ de $\mathrm{C}$, respectivamente. Contrastes: $\mathrm{C} 1$ : controle (-) vs ácido húmico $(\mathrm{AH})$; $\mathrm{C} 2$ : ácido húmico isolado de vermicomposto $(\mathrm{AHv})$ vs ácido húmico isolado de torta de filtro (AHtf).

\section{RESULTADOS}

De posse das médias apresentadas no quadro 2 , foram obtidos os contrastes médios (Quadro 3) conforme Alvarez V. \& Alvarez (2006). Os contrastes médios representam a diferença, em magnitude real, entre a média dos tratamentos comparados para as características morfológicas e nutricionais do abacaxizeiro. Foi possível observar diferenças significativas no crescimento e desenvolvimento do abacaxizeiro propagado in vitro, durante a aclimatação, com a aplicação de $\mathrm{AH}$. O contraste que compara a área foliar das plantas de abacaxi entre o controle e os demais tratamentos (controle vs $\mathrm{AH}$ ) mostrou incremento, em média, de $64,71 \mathrm{~cm}^{2}$. Tal valor corresponde a um incremento de 51,53\% dos tratamentos que receberam $\mathrm{AH}$ sobre o controle. Observa-se que esse efeito é significativo a $1 \%$ de probabilidade pelo teste F (Quadro 3). Nesse sentido, ao comparar o tratamento controle, nota-se que a aplicação de $\mathrm{AH}$ proporcionou incrementos em todas as características morfológicas da parte aérea do abacaxizeiro 'Vitória'. Para exemplificar, observa-se o aumento de 10,12 \% no número de folhas e de 59, $13 \%$ de matéria seca foliar (Quadro 3).

O sistema radicular do abacaxizeiro também foi significativamente alterado com a aplicação de $\mathrm{AH}$ (Quadro 2). Foram observados incrementos na matéria fresca da raiz, matéria seca da raiz e área radicular nos tratamentos com $\mathrm{AH}$, correspondendo a aproximadamente 70,57 e $39 \%$ respectivamente, quando comparado ao controle (Quadro 3).

A promoção do crescimento das mudas resultou, também, em aumentos significativos no conteúdo de N, P, K, Ca e Mg nos tratamentos com AH (Quadro 2), com respectivos valores de, aproximadamente, 52,71 , $50,58,60 \%$, quando comparado ao controle (Quadro 3).

Não houve diferenças significativas, em média, nas variáveis de crescimento e acúmulo de nutrientes para as fontes distintas de AH (Quadro 3).

Os ácidos húmicos não promoveram mudanças qualitativas e quantitativas na organização anatômica da lâmina foliar (Figura 1, Quadros 4 e 5). A anatomia comparada das lâminas foliares do abacaxizeiro 'Vitória', a pós 150 dias de aclimatação, tratadas ou não com $\mathrm{AH}$, foi delimitada por epiderme uniestratificada, com contorno sinuoso das paredes celulares anticlinais (Figura 1a), paredes periclinais externas, com cutícula espessa e corpos silicosos. Abaixo da epiderme, situa-se a hipoderme (Figura 1b). As folhas são hipoestomáticas e os estômatos encontram-se dispostos em faixas paralelas entre os cordões de fibras, com densidade aproximada de 100 estômatos $\mathrm{mm}^{-2}$. Tricomas tectores e escamiformes (Figura 1c) estão presentes em ambas as faces da epiderme. O mesofilo é dorsiventral, apresentando parênquima aquífero, com células grandes e paredes delgadas e, parênquima clorofiliano, com células 
Quadro 2. Características de crescimento da parte aérea, do sistema radicular e acúmulo de nutrientes no abacaxizeiro 'Vitória' em resposta à aplicação de diferentes doses de ácidos húmicos isolados de vermicomposto e de torta de filtro

\begin{tabular}{|c|c|c|c|c|c|c|c|c|c|c|c|c|c|c|c|c|}
\hline \multirow{3}{*}{ Tratamento $^{(1)}$} & \multicolumn{16}{|c|}{ Características de crescimento e acúmulo de nutrientes } \\
\hline & \multicolumn{7}{|c|}{ Parte aérea $^{(2)}$} & \multicolumn{4}{|c|}{ Sistema radicular ${ }^{(3)}$} & \multicolumn{5}{|c|}{ Conteúdo de nutriente ${ }^{(4)}$} \\
\hline & NF & ALT & DR & DC & MFPA & MSPA & AF & MFR & MSR & RPA & AR & $\mathbf{N}$ & $\mathbf{P}$ & $\mathbf{K}$ & $\mathbf{C a}$ & Mg \\
\hline & & $-\mathrm{cn}$ & $n-$ & $\mathrm{mm}$ & $-\mathrm{g} / \mathrm{pla}$ & inta - & $\mathrm{cm}^{2}$ & $-\mathrm{g} / \mathrm{pla}$ & inta - & & $\%$ & & $-\mathrm{n}$ & $\mathrm{ng} / \mathrm{plant}$ & $a$ & \\
\hline$(-)$ & 17,83 & 11,58 & 17,92 & 14,45 & 11,13 & 1,04 & 125,58 & 2,39 & 0,32 & 0,32 & 100,04 & 11,28 & 3,44 & 61,89 & 6,68 & 5,28 \\
\hline $\operatorname{AHv}(10)$ & 21,50 & 14,25 & 25,33 & 18,00 & 20,62 & 1,99 & 215,90 & 4,32 & 0,61 & 0,31 & 165,08 & 21,22 & 7,44 & 113,20 & 12,09 & 11,83 \\
\hline $\operatorname{AHv}(20)$ & 18,83 & 11,75 & 21,83 & 17,39 & 16,64 & 1,63 & 186,80 & 4,53 & 0,55 & 0,33 & 148,23 & 15,58 & 5,38 & 91,45 & 10,03 & 7,66 \\
\hline $\operatorname{AHv}(40)$ & 20,00 & 12,42 & 21,58 & 16,53 & 17,14 & 1,63 & 193,27 & 4,20 & 0,48 & 0,30 & 130,44 & 17,67 & 5,74 & 91,32 & 10,23 & 6,81 \\
\hline $\operatorname{AHtf}(10)$ & 19,00 & 12,17 & 21,25 & 16,43 & 16,28 & 1,52 & 176,91 & 4,20 & 0,47 & 0,31 & 135,95 & 15,36 & 4,71 & 85,15 & 10,23 & 7,96 \\
\hline $\operatorname{AHtf}(20)$ & 19,50 & 12,83 & 21,75 & 16,47 & 17,63 & 1,65 & 190,63 & 3,81 & 0,51 & 0,31 & 139,33 & 16,65 & 6,52 & 92,93 & 10,74 & 8,55 \\
\hline $\operatorname{AHtf}(40)$ & 19,00 & 12,50 & 21,42 & 16,29 & 16,31 & 1,52 & 178,21 & 3,24 & 0,42 & 0,28 & 112,66 & 16,27 & 5,45 & 81,76 & 10,01 & 7,68 \\
\hline
\end{tabular}

(1) Tratamentos: (-): controle; AHv: ácido húmico de vermicomposto; AHtf: ácido húmico de torta de filtro; (10), (20) e (40) são as concentrações de 10, 20 e $40 \mathrm{mmol} \mathrm{L}{ }^{-1}$ de C, respectivamente. ${ }^{(2)}$ Parte aérea: NF: número de folhas; ALT: altura; DR: diâmetro da roseta; DC: diâmetro do caule; MFPA: matéria fresca da parte aérea; MSPA: matéria seca da parte aérea; AF: área foliar. (3) Sistema radicular: MFR: matéria fresca da raiz; MSR: matéria seca da raiz; RPA: razão entre raiz e parte aérea; AR: área radicular, porcentagem sobre o controle. ${ }^{(4)}$ Conteúdo de nutrientes: N, P, K, Ca, Mg: conteúdo de nitrogênio, fósforo, potássio, cálcio, magnésio, respectivamente.

Quadro 3. Contrastes médios, incrementos relativos, quadrado médio do resíduo (QMR) e coeficiente de variação (CV) para as características de crescimento da parte aérea, sistema radicular e acúmulo de nutrientes no abacaxizeiro'Vitória' em resposta à aplicação de diferentes doses de ácidos húmicos isolados de vermicomposto e de torta de filtro

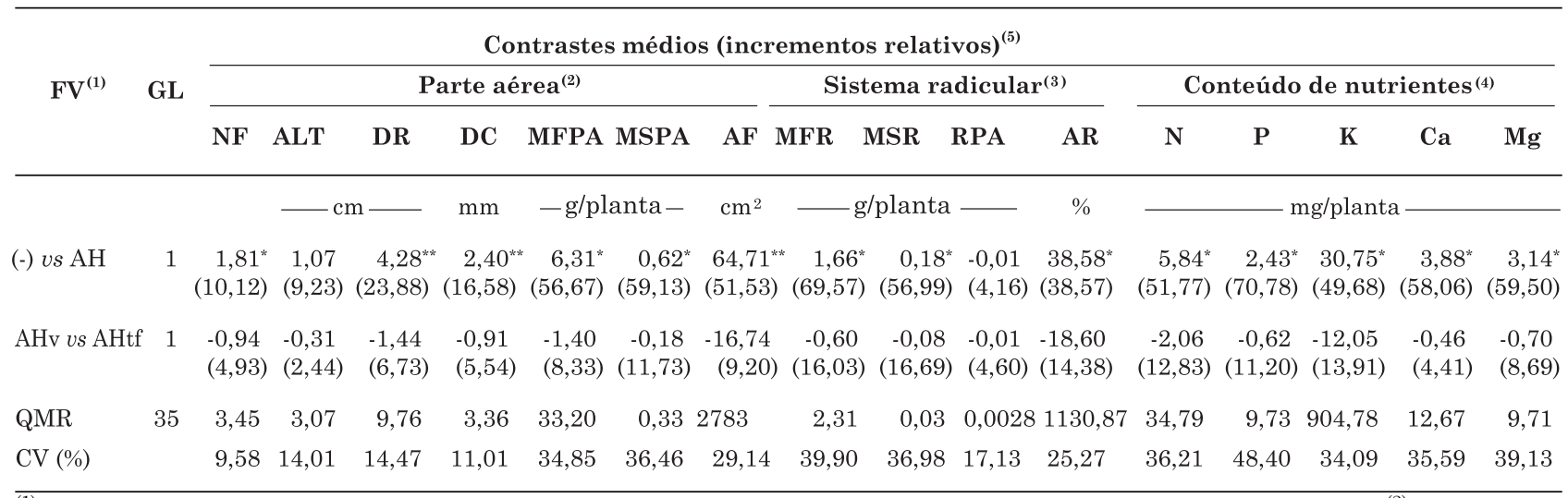

(1) FV: (-): controle; AH: ácido húmico; AHv: ácido húmico de vermicomposto; AHtf: ácido húmico de torta de filtro. ${ }^{(2)}$ Parte aérea: NF: número de folhas; ALT: altura; DR: diâmetro da roseta; DC: diâmetro do caule; MFPA: matéria fresca da parte aérea; MSPA: matéria seca da parte aérea; AF: área foliar. ${ }^{(3)}$ Sistema radicular: MFR: matéria fresca da raiz; MSR: matéria seca da raiz; RPA: razão entre raiz e parte aérea; AR: área radicular. ${ }^{(4)}$ Conteúdo de nutrientes: $\mathrm{N}, \mathrm{P}, \mathrm{K}, \mathrm{Ca}, \mathrm{Mg}$ : conteúdo de nitrogênio, fósforo, potássio, cálcio, magnésio, respectivamente. ${ }^{(5)}$ Incrementos relativos: $100(\mathrm{x}-\mathrm{y}) / \mathrm{y}$, sendo $\mathrm{x}$ a média do tratamento de maior valor e y a média do tratamento de menor valor. ${ }^{*},{ }^{* *}$ : significativo a 5 e $1 \%$ pelo teste F.

pequenas e arredondadas (Figura 1c). Cristais do tipo ráfide (Figura 1d) estão presentes no mesofilo, tanto no parênquima aquífero quanto no parênquima clorofiliano. O parênquima clorofiliano circunda os feixes vasculares colaterais e apresenta cordões de fibras (Figura 1e).
Com relação aos teores dos pigmentos fotossintéticos, incluindo clorofila $a$, clorofila $b$ e carotenoides, em média pouco variaram entre os tratamentos (Quadro 4), não apresentando contrastes significativos (Quadro 5). Entretanto, foi detectado aumento significativo na relação entre clorofila $a$ e 

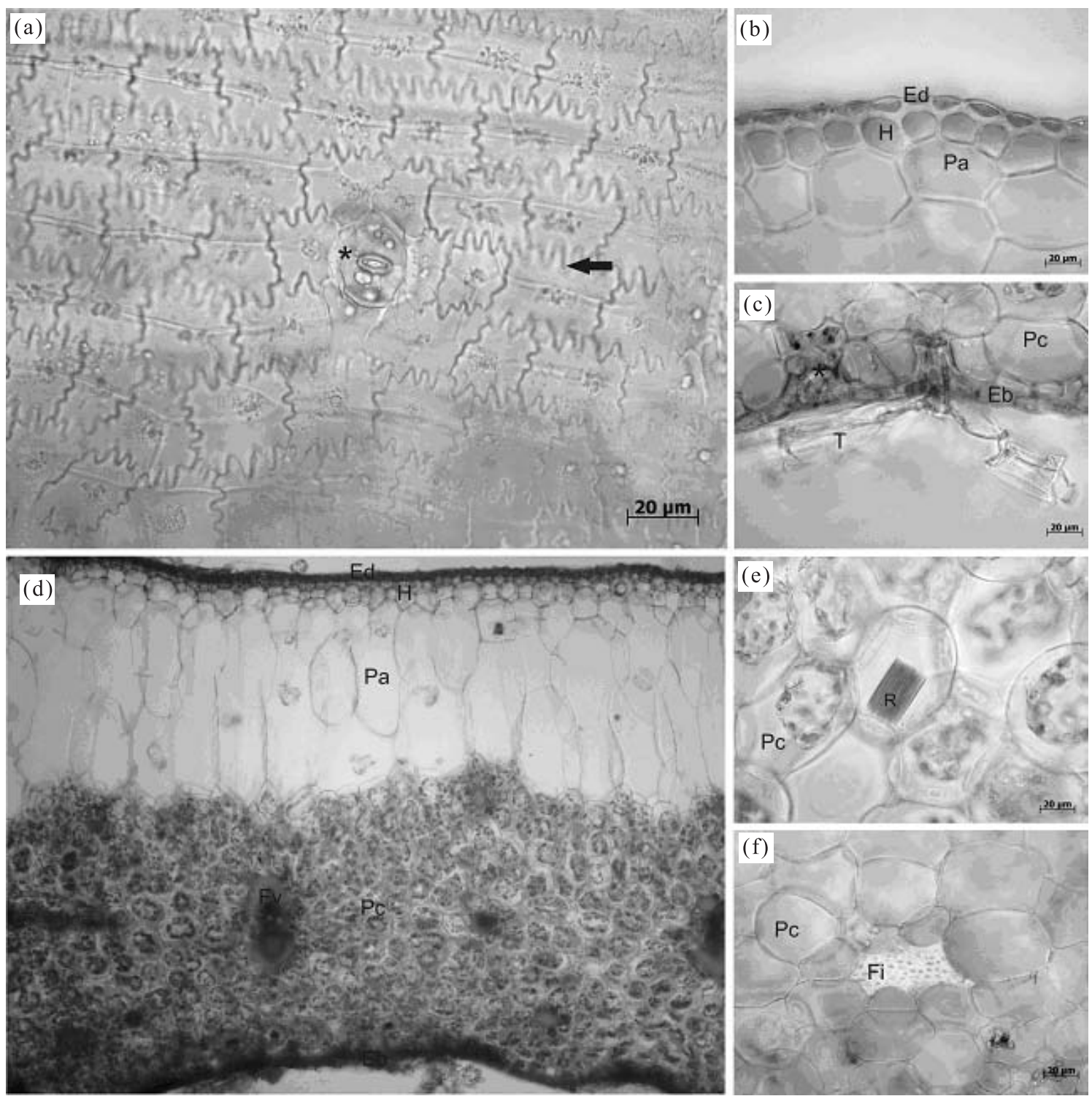

Figura 1. Anatomia da lâmina foliar do abacaxizeiro 'Vitória' tratado com ácidos húmicos. a: vista frontal da epiderme abaxial, mostrando o contorno sinuoso das paredes anticlinais das células epidérmicas (seta) e estômatos (*); b, c, d, e, f: cortes transversais do terço médio da lâmina foliar no eixo central; b: epiderme adaxial (Ed), hipoderme (H) e parênquima aquífero (Pa); c: epiderme abaxial (Eb), parênquima clorofiliano (Pc) e presença de tricomas (T) escamiformes; d: mesofilo diferenciado em parênquima aquífero ( $\mathrm{Pa}$ ) e parênquima clorofiliano ( $\mathrm{Pc}$ ) contendo os feixes vasculares $(\mathrm{Fv})$; e: detalhe dos cristais do tipo ráfide (R); f: detalhe dos cordões de fibra (Fi) presentes no mesofilo. Imagens obtidas por microscopia ótica.

clorofila $b$, com aplicação de $\mathrm{AH}$, com incrementos de $11,54 \%$, quando comparado ao controle (Quadro 5).

Não houve diferença significativa, em média, entre os AH usados para as variáveis anatômicas e para os teores de pigmentos fotossintéticos (Quadro 5).

As respostas das características de crescimento da parte aérea do abacaxizeiro mostraram incrementos curvilineares com taxas quadráticas ou raízes quadráticas, em função do aumento das doses de ácidos húmicos (Quadro 6). Por meio das equações de regressão, foi calculado o acúmulo máximo de matéria seca da parte aérea do abacaxizeiro, para os tratamentos com AHv e AHtf, que foram de 1,85 e de $1,61 \mathrm{~g} \mathrm{planta}^{-1}$, respectivamente. Além disso, com base nas equações de regressão, observou-se que o $\mathrm{AHv}$ proporcionou acúmulo de matéria seca com dose inferior $\left(15,68 \mathrm{mmol} \mathrm{L}^{-1}\right.$ de C) a do AHtf $\left(21,19 \mathrm{mmol} \mathrm{L}^{-1}\right.$ de C), conferindo maior bioatividade ao AHv (Quadro 6). As taxas de incremento (coeficiente angular das equações de regressão) para o AHv foram, de forma geral, superiores àquelas apresentadas pelo $\mathrm{AHtf}$ (Quadro 6). 
De forma análoga ao observado para parte aérea, as curvas de resposta das características de crescimento do sistema radicular, de acúmulo de nutrientes e dos pigmentos fotossintéticos, à aplicação de doses crescentes de $\mathrm{AH}$ apresentaram taxas quadráticas ou raízes quadráticas (Quadro 6).

Quadro 4. Características anatômicas da lâmina foliar e teor de pigmentos fotossintéticos do abacaxizeiro 'Vitória' em resposta à aplicação de diferentes doses de ácidos húmicos isolados de vermicomposto e de torta de filtro

\begin{tabular}{|c|c|c|c|c|c|c|c|c|c|c|}
\hline \multirow{2}{*}{ Tratamento $^{(1)}$} & \multicolumn{3}{|c|}{ Característica anatômica ${ }^{(2)}$} & \multicolumn{7}{|c|}{ Pigmentos fotossintéticos ${ }^{(3)}$} \\
\hline & N. estom. & P. aquífero & P. clorofil. & Cla & $\mathrm{Cl} b$ & $\mathrm{Cl} t$ & Car & $\mathrm{Cl} a / \mathrm{Cl} b$ & $\mathrm{Cl} t / \mathrm{Car}$ & SPAD \\
\hline & & 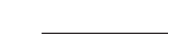 & & 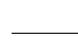 & $-\mu \mathrm{g} \mathrm{r}$ & $\mathrm{L}^{-1}$ & & & & \\
\hline$(-)$ & 12,17 & 625,67 & 717,00 & 3,47 & 1,17 & 4,65 & 1,15 & 3,00 & 4,03 & 37,03 \\
\hline $\operatorname{AHv}(10)$ & 12,83 & 703,67 & 752,67 & 3,65 & 1,19 & 4,83 & 1,20 & 3,15 & 4,02 & 39,25 \\
\hline $\operatorname{AHv}(20)$ & 12,83 & 640,83 & 715,33 & 3,68 & 1,13 & 4,82 & 1,13 & 3,31 & 4,21 & 37,25 \\
\hline $\operatorname{AHv}(40)$ & 12,50 & 664,83 & 751,17 & 4,42 & 1,34 & 5,76 & 1,31 & 3,29 & 4,36 & 40,00 \\
\hline $\operatorname{AHtf}(10)$ & 12,17 & 623,00 & 731,17 & 3,97 & 1,14 & 5,10 & 1,18 & 3,57 & 4,28 & 39,18 \\
\hline $\operatorname{AHtf}(20)$ & 12,00 & 692,83 & 720,17 & 3,46 & 1,05 & 4,51 & 1,11 & 3,35 & 4,06 & 38,22 \\
\hline $\operatorname{AHtf}(40)$ & 12,50 & 682,00 & 733,50 & 3,60 & 1,08 & 4,68 & 1,19 & 3,39 & 3,93 & 42,17 \\
\hline
\end{tabular}

(1) Tratamentos: (-), controle; AHv, ácido húmico de vermicomposto; AHtf, ácido húmico de torta de filtro; (10), (20) e (40) são as concentrações de 10, 20 e $40 \mathrm{mmol} \mathrm{L}^{-1}$ de $\mathrm{C}$, respectivamente. ${ }^{(2)}$ Características anatômicas: N. estom.: número de estômatos; P. aquífero: comprimento do parênquima aquífero; P. clorofil.: comprimento do parênquima clorofiliano. ${ }^{(3)}$ Pigmentos fotossintéticos: Cla: clorofila $a$; $\mathrm{Cl} b$ : clorofila $b$; Clt: clorofila total; Car: carotenoides; $\mathrm{Cl} a / \mathrm{Cl} b$ : razão entre clorofila $a$ e clorofila $b$; $\mathrm{Cl} t / \mathrm{Car}$ : razão entre clorofila total e carotenoide; SPAD: teor de clorofila pelo índice SPAD (medição da intensidade da cor vede).

Quadro 5. Contrastes médios, incrementos relativos, quadrado médio do resíduo (QMR) e coeficiente de variação $(\mathrm{CV})$ para as características anatômicas da lâmina foliar e o teor de pigmentos fotossintéticos do abacaxizeiro'Vitória' em resposta à aplicação de diferentes doses de ácidos húmicos isolados de vermicomposto e de torta de filtro

\begin{tabular}{|c|c|c|c|c|c|c|c|c|c|c|c|}
\hline \multirow{3}{*}{$\mathrm{FV}^{(1)}$} & \multirow{3}{*}{ GL } & \multicolumn{8}{|c|}{ Contrastes médios (incrementos relativos) ${ }^{(4)}$} & & \\
\hline & & \multicolumn{3}{|c|}{ Características anatômicas ${ }^{(2)}$} & \multicolumn{7}{|c|}{ Pigmentos fotossintéticos ${ }^{(3)}$} \\
\hline & & N. estom. & P. aquífero & P. clorof. & $\overline{\mathrm{Cl} a}$ & $\mathrm{Cl} b$ & $\mathrm{Cl} t$ & Car & $\mathrm{Cl} a / \mathrm{Cl} b$ & $\mathrm{Cl} t / \mathrm{Car}$ & SPAD \\
\hline & & & \multicolumn{2}{|c|}{$\mu \mathrm{m}$} & \multicolumn{4}{|c|}{$\mu \mathrm{g} \mathrm{mL}^{-1}$} & & & \\
\hline (-) vs $\mathrm{AH}$ & 1 & $\begin{array}{c}0,31 \\
(2,51)\end{array}$ & $\begin{array}{c}42,19 \\
(6,74)\end{array}$ & $\begin{array}{l}17,00 \\
(2,37)\end{array}$ & $\begin{array}{c}0,32 \\
(9,25)\end{array}$ & $\begin{array}{l}-0,02 \\
(1,53)\end{array}$ & $\begin{array}{c}0,30 \\
(6,54)\end{array}$ & $\begin{array}{c}0,04 \\
(3,55)\end{array}$ & $\begin{array}{c}0,35^{\text {** }} \\
(11,54)\end{array}$ & $\begin{array}{c}0,11 \\
(2,76)\end{array}$ & $\begin{array}{r}2,31 \\
(6,24)\end{array}$ \\
\hline AHv vs AHtf & 1 & $\begin{array}{l}-0,50 \\
(4,09)\end{array}$ & $\begin{array}{l}-3,83 \\
(0,58)\end{array}$ & $\begin{array}{r}-11,44 \\
(1,57)\end{array}$ & $\begin{array}{l}-0,24 \\
(6,54)\end{array}$ & $\begin{array}{c}-0,13 \\
(12,06)\end{array}$ & $\begin{array}{l}-0,37 \\
(7,80)\end{array}$ & $\begin{array}{l}-0,06 \\
(4,90)\end{array}$ & $\begin{array}{c}0,19 \\
(5,42)\end{array}$ & $\begin{array}{l}-0,10 \\
(2,50)\end{array}$ & $\begin{array}{l}1,02 \\
(2,63)\end{array}$ \\
\hline QMR & 35 & 1,55 & 10342,11 & 4670,65 & 0,821 & 0,111 & 1,50 & 0,049 & 0,106 & 0,233 & 32,47 \\
\hline CV $(\%)$ & & 10,03 & 15,37 & 9,34 & 24,17 & 28,80 & 24,99 & 18,70 & 9,87 & 11,70 & 14,60 \\
\hline
\end{tabular}

(1) FV: (-), controle; AH, ácido húmico; AHv, ácido húmico de vermicomposto; AHtf, ácido húmico de torta de filtro. ${ }^{(2)}$ Características anatômicas: N. estom.: número de estômatos; P. aquífero: parênquima aquífero; P. clorofil.: parênquima clorofiliano. ${ }^{(3)}$ Pigmentos fotossintéticos: Cla: clorofila $a$; $\mathrm{Cl} b$ : clorofila $b$; Clt: clorofila total; Car: carotenoides; Cla/Clb: razão entre clorofila $a$ e clorofila $b$; Clt/Car: razão entre clorofila total e carotenoides; SPAD: teor de clorofila pelo índice SPAD (medição da intensidade da cor verde). ${ }^{(4)}$ Incrementos relativos: $100(\mathrm{x}-\mathrm{y}) / \mathrm{y}$, sendo $\mathrm{x}$ a média do tratamento de maior valor e y a média do tratamento de menor valor. ${ }^{* *}$ : significativo a $1 \%$ pelo teste $\mathrm{F}$.

Quadro 6. Equações de regressão para as características de crescimento, acúmulo de nutrientes e de pigmentos fotossintéticos do abacaxizeiro 'Vitória' em resposta à aplicação de diferentes doses de ácidos húmicos isolados de vermicomposto e de torta de filtro

\begin{tabular}{cccc}
\hline Variável $^{(1)}$ & Desdobramento $^{(2)}$ & Equação de regressão & $\mathbf{R}^{2}$ \\
\hline \multirow{2}{*}{$\mathrm{NF}$} & $\mathrm{AHv}$ & Crescimento da parte aérea \\
& $\mathrm{AHtf}$ & $\hat{\mathrm{y}}=\overline{\mathrm{y}}=19,54$ & 0,998 \\
\hline
\end{tabular}




\section{Quadro 6. Continuação}

\begin{tabular}{|c|c|c|c|}
\hline Variável $^{(1)}$ & Desdobramento $^{(2)}$ & Equação de regressão & $\mathbf{R}^{2}$ \\
\hline ALT & $\begin{array}{l}\mathrm{AHv} \\
\mathrm{AHtf}\end{array}$ & $\begin{array}{l}\text { Crescimento da parte aérea } \\
\hat{\mathrm{y}}=\overline{\mathrm{y}}=12,21 \\
\hat{\mathrm{y}}=11,5311-0,0951 \mathrm{x}-0,0018 \mathrm{x}^{2}\end{array}$ & 0,961 \\
\hline DR & $\begin{array}{l}\mathrm{AHv} \\
\mathrm{AHtf}\end{array}$ & $\begin{array}{l}\hat{y}=18,1408+3,1221 x^{0,5}-0,4211 x \\
\hat{y}=17,9135+1,5688 x^{0,5}-0,1603 x\end{array}$ & $\begin{array}{l}0,778 \\
0,999\end{array}$ \\
\hline $\mathrm{DC}$ & $\begin{array}{l}\mathrm{AHv} \\
\mathrm{AHtf}\end{array}$ & $\begin{array}{l}\hat{y}=14,1493+1,7303 \mathrm{x}^{0,5}-0,4211 \mathrm{x} \\
\hat{\mathrm{y}}=14,4624+0,9126 \mathrm{x}^{0,5}-0,0993 \mathrm{x}\end{array}$ & $\begin{array}{l}0,971 \\
0,995\end{array}$ \\
\hline MFPA & $\begin{array}{l}\mathrm{AHv} \\
\mathrm{AHtf}\end{array}$ & $\begin{array}{l}\hat{y}=11,4073+3,8215 x^{0,5}-0,4778 x \\
\hat{y}=11,0794+2,6534 x^{0,5}-0,2859 x\end{array}$ & $\begin{array}{l}0,795 \\
0,995\end{array}$ \\
\hline MSPA & $\begin{array}{l}\mathrm{AHv} \\
\mathrm{AHtf}\end{array}$ & $\begin{array}{l}\hat{y}=1,0649+0,3952 x^{0,5}-0,0499 x \\
\hat{y}=1,0355+0,2495 x^{0,5}-0,0271 x\end{array}$ & $\begin{array}{l}0,837 \\
0,989\end{array}$ \\
\hline $\mathrm{AF}$ & $\begin{array}{l}\mathrm{AHv} \\
\mathrm{AHtf}\end{array}$ & $\begin{array}{l}\hat{y}=127,8480+36,4116 x^{0,5}-4,2588 x \\
\hat{y}=125,0960+26,2723 x^{0,5}-2,7970 x\end{array}$ & $\begin{array}{l}0,860 \\
0,989\end{array}$ \\
\hline MFR & $\begin{array}{l}\mathrm{AHv} \\
\mathrm{AHtf}\end{array}$ & $\begin{array}{c}\text { Crescimento da raiz } \\
\hat{y}=2,3877+0,9391 \mathrm{x}^{0,5}-0,1031 \mathrm{x} \\
\hat{\mathrm{y}}=2,4106+0,9101 \mathrm{x}^{0,5}-0,1244 \mathrm{x}\end{array}$ & $\begin{array}{l}0,999 \\
0,967\end{array}$ \\
\hline MSR & $\begin{array}{l}\text { AHv } \\
\text { AHtf }\end{array}$ & $\begin{array}{l}\hat{\mathrm{y}}=0,3255+0,1374 \mathrm{x}^{0,5}-0,0181 \mathrm{x} \\
\hat{\mathrm{y}}=0,3265+0,0171 \mathrm{x}-0,0004 \mathrm{x}^{2}\end{array}$ & $\begin{array}{l}0,961 \\
0,986\end{array}$ \\
\hline $\mathrm{R} / \mathrm{PA}$ & $\begin{array}{l}\mathrm{AHv} \\
\mathrm{AHtf}\end{array}$ & $\begin{array}{l}\hat{y}=\bar{y}=0,32 \\
\hat{y}=0,3187-0,0003 x-0,00002 x^{2}\end{array}$ & 0,948 \\
\hline $\mathrm{AR}$ & $\begin{array}{l}\mathrm{AHv} \\
\mathrm{AHtf}\end{array}$ & $\begin{array}{l}\hat{y}=101,026+31,9591 x^{0,5}-4,3777 x \\
\hat{y}=99,6385+22,4674 x^{0,5}-0,0320 x\end{array}$ & $\begin{array}{l}0,949 \\
0,982\end{array}$ \\
\hline $\mathrm{N}$ & $\begin{array}{l}\mathrm{AHv} \\
\mathrm{AHtf}\end{array}$ & $\begin{aligned} & \text { Acúmulo de nutrientes } \\
\hat{y}= & 11,6765+3,5332 \mathrm{x}^{0,5}-0,4325 \mathrm{x} \\
\hat{\mathrm{y}}= & 11,2464+1,9464 \mathrm{x}^{0,5}-0,1800 \mathrm{x}\end{aligned}$ & $\begin{array}{l}0,635 \\
0,991\end{array}$ \\
\hline $\mathrm{P}$ & $\begin{array}{l}\mathrm{AHv} \\
\mathrm{AHtf}\end{array}$ & $\begin{array}{l}\hat{y}=3,57784+1,55220 x^{0,5}-0,00199 x \\
\hat{y}=3,26565+0,23491 x^{0,5}-0,00447 x\end{array}$ & $\begin{array}{l}0,709 \\
0,927\end{array}$ \\
\hline $\mathrm{K}$ & $\begin{array}{l}\text { AHv } \\
\text { AHtf }\end{array}$ & $\begin{array}{l}\hat{y}=63,3534+21,3370 x^{0,5}-0,0276 x \\
\hat{y}=62,4274+2,6786 x^{0,5}-0,0549 x\end{array}$ & $\begin{array}{l}0,804 \\
0,993\end{array}$ \\
\hline $\mathrm{Ca}$ & $\begin{array}{l}\mathrm{AHv} \\
\mathrm{AHtf}\end{array}$ & $\begin{array}{l}\hat{y}=6,8244+2,2117 x^{0,5}-0,2735 x \\
\hat{y}=6,6674+1,7632 x^{0,5}-0,1947 x\end{array}$ & $\begin{array}{l}0,827 \\
0,999\end{array}$ \\
\hline $\mathrm{Mg}$ & $\begin{array}{l}\text { AHv } \\
\text { AHtf }\end{array}$ & $\begin{array}{l}\hat{y}=5,5128+2,8573 x^{0,5}-0,4338 x \\
\hat{y}=5,2522+1,4223 x^{0,5}-0,1628 x\end{array}$ & $\begin{array}{l}0,710 \\
0,990\end{array}$ \\
\hline $\begin{array}{l}\mathrm{Cl} a \\
\mathrm{Cl} b\end{array}$ & $\begin{array}{l}\text { AHv } \\
\text { AHtf } \\
\text { AHv } \\
\text { AHtf }\end{array}$ & $\begin{array}{l}\quad \text { Pigmentos fotossintéticos } \\
\hat{\mathrm{y}}=3,5038+0,0013 \mathrm{x}-0,0005 \mathrm{x}^{2} \\
\hat{\mathrm{y}}=\overline{\mathrm{y}}=3,63 \\
\hat{\mathrm{y}}=1,1859-0,0063 \mathrm{x}+0,0003 \mathrm{x}^{2} \\
\hat{\mathrm{y}}=1,1826-0,0086 \mathrm{x}-0,0001 \mathrm{x}^{2}\end{array}$ & $\begin{array}{l}0,980 \\
0,909 \\
0,860\end{array}$ \\
\hline $\mathrm{Cl} t$ & $\begin{array}{l}\mathrm{AHv} \\
\mathrm{AHtf}\end{array}$ & $\begin{array}{l}\hat{y}=4,6897-0,0049 x+0,0008 x^{2} \\
\hat{y}=\bar{y}=4,74\end{array}$ & 0,970 \\
\hline Car & $\begin{array}{l}\text { AHv } \\
\text { AHtf }\end{array}$ & $\begin{array}{l}\hat{y}=1,1645-0,0031 x-0,0002 x^{2} \\
\hat{y}=\bar{y}=1,16\end{array}$ & 0,806 \\
\hline $\mathrm{Cl} a / \mathrm{Cl} b$ & $\begin{array}{l}\mathrm{AHv} \\
\mathrm{AHtf}\end{array}$ & $\begin{array}{l}\hat{y}=2,9886+0,0225 x-0,0004 x^{2} \\
\hat{y}=3,0143+0,2294 x^{0,5}-0,0278 x\end{array}$ & $\begin{array}{l}0,982 \\
0,821\end{array}$ \\
\hline $\mathrm{Cl} t / \mathrm{Car}$ & $\begin{array}{l}\text { AHv } \\
\text { AHtf }\end{array}$ & $\begin{array}{l}\hat{y}=4,0272-0,0318 x^{0,5}-0,0136 x \\
\hat{y}=4,0432+0,1291 x^{0,5}-0,0237 x\end{array}$ & $\begin{array}{l}0,944 \\
0,809\end{array}$ \\
\hline SPAD & $\begin{array}{l}\mathrm{AHv} \\
\mathrm{AHtf}\end{array}$ & $\begin{array}{l}\hat{y}=\bar{y}=38,38 \\
\hat{y}=37,4488+0,0454 x-0,0017 x^{2}\end{array}$ & 0,854 \\
\hline
\end{tabular}

(1) Variável NF: número de folhas; ALT: altura $(\mathrm{cm})$; DR: diâmetro da roseta (cm); DC: diâmetro do caule (mm); MFPA: matéria fresca da parte aérea (g/planta); MSPA: matéria seca da parte aérea (g/planta); AF: área foliar $\left(\mathrm{cm}^{2}\right)$; MFR: matéria fresca da raiz (g); MSR: matéria seca da raiz (g/planta); RPA: razão entre raiz e parte aérea; AR: área radicular (\%); N, P, K, Ca, Mg: conteúdo de nitrogênio, fósforo, potássio, cálcio, magnésio, respectivamente (g/planta); Cla: clorofila $\left.a(\mu \mathrm{g} \mathrm{mL})^{-1}\right)$; Clb: clorofila $b\left(\mu \mathrm{g} \mathrm{mL}{ }^{-1}\right)$; $\mathrm{Cl} t$ : clorofila total $\left(\mu \mathrm{g} \mathrm{mL}^{-1}\right)$; Car: carotenoides $\left(\mu \mathrm{g} \mathrm{mL}{ }^{-1}\right)$; Cla/Clb: razão entre clorofila $a$ e clorofila $b$; Clt $t$ Car: razão entre clorofila total e carotenoides; SPAD: teor de clorofila pelo índice SPAD (medição da intensidade da cor verde). ${ }^{(2)}$ Desdobramento: AHv: ácido húmico de vermicomposto; AHtf: ácido húmico de torta de filtro. 


\section{DISCUSSÃO}

O abacaxizeiro 'Vitória', lançado pela Embrapa Mandioca e Fruticultura Tropical e pelo Instituto Capixaba de Pesquisa, Assistência Técnica e Extensão Rural, em 2006, apresenta como características principais, resistência à fusariose, folhas sem espinhos, frutos cilíndricos com casca amarelada, polpa branca com elevado teor de açúcar e bom perfilhamento (INCAPER, 2006). Com relação à anatomia foliar, foram observadas (Figura 1) características semelhantes às descritas para outros cultivares de Ananas comosus, como tricomas escamiformes, epiderme uniestratificada revestida por cutícula, contorno sinuoso das paredes anticlinais das células epidérmicas, corpos silicosos, ráfides, hipoderme, mesofilo constituído de parênquima aquífero e clorofiliano, cordões de fibras, e estômatos na face epidérmica abaxial dispostos no sentido longitudinal de forma paralela (Py, 1969; d'Eeckenbrugge \& Leal, 2003; Barboza et al., 2006; Proença \& Sajo, 2007). Essas características anatômicas, invariavelmente, levam à retenção de água na planta, que pode ser explicada pela hipoderme, pelo parênquima aquífero, pelos tricomas escamiformes e folhas hipoestomáticas (Larcher, 2000; Appezzato-da-Glória \& CarmelloGuerreiro, 2003; d'Eeckenbrugge \& Leal, 2003). Outras levam à dissipação de energia luminosa, como tricomas escamiformes, que refletem a luz (Py, 1969; Larcher, 2000; d'Eeckenbrugge \& Leal, 2003).

A presença constante de cristais de oxalato de cálcio, do tipo ráfide, nas células do mesofilo e corpos silicosos nas células epidérmicas do abacaxizeiro 'Vitória' também podem ser consideradas características anatômicas, que auxiliam na reflexão da luz (Franceschi \& Horner, 1980; Proença \& Sajo, 2007). Tais características são favoráveis à melhor tolerância às condições ambientais e não foram afetadas pela aplicação de $\mathrm{AH}$ durante a aclimatação.

O período de aclimatação do abacaxizeiro é considerado crítico por causa da lentidão do crescimento do sistema radicular e da parte aérea (Moreira, 2001; Barboza et al., 2006). A aplicação de $\mathrm{AH}$, durante a aclimatação, resultou em incrementos significativos no crescimento e desenvolvimento das plantas em relação ao controle. Também foram observados aumentos nos conteúdos nutricionais de N, P, K, Ca e Mg (Quadros 2 e 3).

$\mathrm{O}$ uso do AHv na promoção do crescimento vegetal está bem documentado (Cacco \& Dell'Agnola, 1984; Dell'Agnola \& Nardi, 1987; Nardi et al., 1996; Muscolo \& Nardi, 1997; Masciandaro et al., 1999; Muscolo et al., 1999; Façanha et al., 2002; Canellas et al, 2002; Quaggiotti et al., 2004; Canellas et al., 2006; Rodda et al., 2006; Zandonadi et al., 2007,). Neste trabalho, não foram observadas diferenças no crescimento e acúmulo de nutrientes, entre as diferentes fontes de AH. Há pouca informação sobre a ação de AHtf, mas é possível que AHtf represente uma alternativa às limitações de disponibilidade de esterco para a vermicompostagem, nas áreas de produção de canade-açúcar (Marques Júnior et al., 2008).

Grande parte dos efeitos bioestimulantes dos ácidos húmicos tem sido creditado à sua atividade similar à de hormônios vegetais da classe das auxinas, ou seja, podem promover o crescimento vegetal em concentrações relativamente pequenas. Alguns mecanismos de ação têm sido propostos para explicar a indução do crescimento radicular pelos $\mathrm{AH}$, como a formação de complexos solúveis, com cátions na rizosfera (Chen \& Avaid, 1990) e um suposto aumento da permeabilidade da membrana plasmática pela ação surfactante dos AH (Visser, 1983). Se, por um lado, a alteração da propriedade de permeabilidade seletiva da plasmalema em tese pode aumentar a entrada de íons, por outro pode favorecer também a saída, uma vez que a ação surfactante não preserva a seletividade das membranas (Nardi et al., 2002).

Canellas et al. (2008) verificaram que plântulas de milho, tratadas com AHv, modificam o seu perfil de exsudação radicular de ácidos orgânicos, aumentando, significativamente, a extrusão de ácido cítrico e oxálico. Em contato com o ambiente acidificado da rizosfera, as partículas supraestruturais dos ácidos húmicos podem se fragmentar e gerar subunidades potencialmente capazes de alterar o metabolismo celular, por meio da ativação de $\mathrm{H}^{+}$. ATPases da membrana plasmática de células de raiz (Piccolo, 2001; Façanha et al., 2002; Canellas et al., 2006). A atividade desses mecanismos leva à acidificação do apoplasto e a ativação de exoenzimas degradadoras de parede celular, tornando-a mais susceptível à ação da pressão de turgescência vacuolar. Com isso, ocorre a expansão celular e, por consequência, a do tecido radicular (Hager et al., 1991; Frias et al., 1996). Tal mecanismo pode explicar os resultados obtidos, isto é, promoção do desenvolvimento radicular e acúmulo de nutrientes das plantas de abacazixeiro submetidas à aplicação de AH (Quadro 2 e 3). É possível que a ativação das $\mathrm{H}^{+}$-ATPases pelos AH promova a despolarização da membrana plasmática e, com isso, a ativação de transportadores secundários responsáveis pelo incremento da absorção de macro e micronutrientes (Sondergaard et al., 2004).

Somados aos aspectos de crescimento e nutricionais, possíveis efeitos fisiológicos, manifestados pela quantificação de pigmentos fotossintéticos na presença de $\mathrm{AH}$, aplicado na parte aérea foram avaliados. Os tratamentos com ácidos húmicos proporcionaram maiores teores de pigmentos fotossintéticos e um acréscimo significativo na razão entre clorofila $a$ e clorofila $b$, quando comparados ao controle (Quadros 4 e 5). Esse fato indica que a aplicação de AH no abacaxizeiro 'Vitória', durante o processo de aclimatação, favorece o estabelecimento das plantas ex vitro e, possivelmente, o posterior estabelecimento no campo. Incrementos nos teores 
de clorofila decorrentes da aplicação foliar de AH (5 e $20 \mathrm{mg} \mathrm{L}^{-1}$ ) em videiras 'Itália' foram observados previamente por Ferrara \& Brunetti (2008), que, no entanto, verificaram diminuição da razão entre clorofila $a$ e clorofila $b$. Por outro lado, Liu et al. (1998) verificaram que a aplicação de ácidos húmicos $(0,100$, 200, $400 \mathrm{mg} \mathrm{L}^{-1}$ ) na gramínea Agrostis stolonifera não alterou o teor de clorofila, apesar de ter afetado o processo fotossintético. As diferenças encontradas na literatura (Liu et al., 1998; Ferrara \& Brunetti, 2008) indicam a presença de interações entre os fatores: fonte e dose de AH, genótipo e ambiente de cultivo.

Neste trabalho, as curvas de respostas à aplicação de doses crescentes de ácidos húmicos apresentaram variação quadrática e raiz quadrática, evidenciando o efeito "dose dependente" dos AH no desenvolvimento das plantas. Os resultados indicam a possibilidade do uso de AH na aceleração do crescimento vegetal, durante a fase de aclimatação das plantas propagadas in vitro de abacaxizeiro, o que pode representar uma alternativa importante para a agricultura orgânica ou para a redução de custos de produção, com base na maior eficiência de absorção dos nutrientes e crescimento.

\section{CONCLUSÕES}

1. Ácidos húmicos isolados de vermicomposto e de torta de filtro promoveram o crescimento vegetal de plantas originadas de cultura in vitro de abacaxizeiro 'Vitória', na fase de aclimatação, uma vez que foram observados incrementos no crescimento da parte aérea, do sistema radicular e nos conteúdos de N, P, $\mathrm{K}, \mathrm{Ca}$ e $\mathrm{Mg}$, além de resultar em aumento da relação clorofila a/clorofila $b$.

2. Os ácidos húmicos isolados de vermicomposto se mostraram mais bioativos que os de torta de filtro, já que promovem o crescimento vegetal de plantas de abacaxizeiro com menor dose aplicada $\left(15 \mathrm{mmol} \mathrm{L}^{-1}\right.$ de C).

3. A promoção do crescimento das mudas de abacaxizeiro propagadas in vitro pela aplicação de ácidos húmicos pode melhorar a adaptação das plântulas ao ambiente ex vitro, reduzindo o período de aclimatação.

\section{AGRADECIMENTOS}

Os autores agradecem ao Laboratório BioMudas pelo fornecimento das mudas in vitro de abacaxizeiro; ao $\mathrm{CNPq}$ (projetos n. 484671/2007-3 e 308368/20070), Instituto Milênio MCT/CNPq, FAPERJ e IFS pelo auxílio financeiro; ao professor Dr. Pedro Henrique Monnerat (UENF) e ao Sr. José Acácio da Silva (UENF) pela colaboração nas análises nutricionais.

\section{LITERATURA CITADA}

ABRAMOFF, M.D.; MAGELHAES, P.J. \& RAM, S.J. "Image processing with ImageJ”. Biophotonics Inter., 11:36-42, 2004.

ALMEIDA, W.A.B.; SANTANA G.S.; RODRIGUEZ, A.P.M. \& COSTA, M.A.P.C. Optimization of a protocol for the micropropagation of pineapple. R. Bras. Frutic., 24:296300, 2002 .

ALVAREZ V., V.H. \& ALVAREZ, G.A.M. Comparações de médias ou testes de hipóteses? Contrastes! B. Inf. SBCS, $31: 24-34,2006$.

APPEZZATO-DA-GLÓRIA, B. \& CARMELLO-GUERREIRO, S.M. Anatomia vegetal. Viçosa, MG, Universidade Federal de Viçosa, 2003. 438p.

BALDOTTO, M.A.; CANELLAS, L.P.; CANELA, M.C.; SIMÕES, M.L.; MARTIN-NETO, L.; FONTES, M.P.F. \& VELLOSO A.C.X. Propriedades redox e grupos funcionais de ácidos húmicos isolados de adubos orgânicos. R. Bras. Ci. Solo, 31:465-475, 2007.

BARBOZA, S.B.S.C.; CALDAS, L.S. \& SOUZA, L.A.C. Micropropagação do híbrido PExSC-52 e do cultivar Smooth Cayenne de abacaxizeiro. Pesq. Agropec. Bras., 39:725-733, 2004.

BARBOZA, S.B.S.C.; GRACIANO RIBEIRO, D.; TEIXEIRA, J.B.; PORTES, T.A. \& SOUZA, L.A.C. Anatomia foliar de plantas micropropagadas de abacaxi. Pesq. Agropec. Bras., 41:185-194, 2006.

BREGONCI, I.S.; SCHMILDT, E.R.; COELHO, R.I.; REIS, E.F.; BRUM, V.J. \& SANTOS, J.G. Adubação foliar com macro e micronutrientes no crescimento de mudas micropropagadas do abacaxizeiro cv. Gold [Ananas comosus (L.) Merrill] em diferentes recipientes. Ci. Agrotec., 32:705-711, 2008.

BUSATO, J.G. Química do húmus e fertilidade do solo após adição de adubos orgânicos. Campos dos Goytacazes, Universidade Estadual do Norte Fluminense Darcy Ribeiro, 2008. 135p. (Tese de Doutorado)

CACCO, G. \& DELL'AGNOLA, G. Plant growth regulator activity of soluble humic complexes. Can. J. Soil Sci., 64:225-228, 1984.

CAMPOSTRINI, E. \& OTONI, W.C. Aclimatação de mudas: Abordagens recentes. Brasilia, CNPH/Embrapa, 1996. 12p. (ABCTP Noticias, 25)

CANELLAS, L.P.; FAÇANHA, A.O.; FAÇANHA, A.R. \& OLIVARES, F.L. Humic acids isolated from earthworm induces root mitotic sites and plasma membrane $\mathrm{H}^{+}$. ATPase. Plant Physiol., 30:1951-1957, 2002.

CANELLAS, L.P.; TEIXEIRA JUNIOR, L.R.L.; DOBBSS, L.B.; SILVA, C.A.; MÉDICI, L.O.; ZANDONADI, D.B. \& FAÇANHA, A.R. Humic acids crossinteractions with root and organic acids. Ann. Appl. Biol., 153:157-166, 2008.

CANELLAS, L.P.; ZANDONADI, D.B.; OLIVARES, F.L. \& FAÇANHA, A.R. Efeitos fisiológicos de substâncias húmicas - o estímulo às $\mathrm{H}^{+}$-ATPases. In: FERNANDES, M.S., org. Nutrição mineral de plantas. Viçosa, MG, Sociedade Brasileira de Ciência do Solo, 2006. p.175-200. 
CATUNDA, P.E.A.; MARINHO, C.S.; GOMES, M.M.A. \& CARVALHO, A.J.C. Brassinosteróide e substratos na aclimatação do abacaxizeiro 'Imperial'. Acta Sci. Agron., 30:345-352, 2008.

CHEN, Y. \& AVAID, T. Effects of humic substances on plant growth. In: MaCCARTHY, P.; CAPP, C.E.; MALCOLM, R.L. \& BLOOM, P.R., eds. Humic substances in soil and crop sciences: Selected readings. Madison, American Society of America, 1990. p.161-186.

CHEN, Y.; CLAPP, C.E. \& MAGEN, H. Mechanisms of plant growth stimulation by humic substances: The role of organo-iron complexes. Soil Sci. Plant Nutr., 50:1089-1095, 2004 .

D’EECKENBRUGGE, G.C. \& LEAL, F. Morphology, anatomy and taxonomy. In: BARTHOLOMEW, D.P.; PAULL, R.E \& ROHRBACH, K.G., eds. The pineapple: Botany, production and uses. New York, CAB International, 2003. p.13-32.

DELFINE, S.; TOGNETTI, R.; DESIDERIO, E. \& ALVINO, A. Effects of foliar application of $\mathrm{N}$ and humic acids on growth and yield of durum wheat. Agron. Sustain. Develop. 25:183-191, 2005.

DELL'AGNOLA, G. \& NARDI, S. On overview of earthworm activity in the soil. In: BONVICINI PAGLIAI, A.M. \& OMODEO, P., eds. On earthworms selected symposia and monographs. Part 2. Modena, Mucchi, 1987. p.103112 .

FAÇANHA, A.R.; FAÇANHA, A.L.O.; OLIVARES, F.L.; GURIDI, F.; SANTOS, G.A.; VELLOSO, A.C.X.; RUMJANEK, V.M.; BRASIL, F.; SCHRIPSEMA, J.; BRAZ-FILHO, R.; OLIVEIRA, M.A. \& CANELLAS, L.P. Bioatividade de ácidos húmicos: Efeito sobre o desenvolvimento radicular e sobre a bomba de prótons da membrana plasmática. Pesq. Agropec. Bras., 37:13011310, 2002 .

FERRARA, G. \& BRUNETTI, G. Influence of foliar applications of humic acids on yield and fruit quality of table grape cv. Itália. J. Intern. Sci. Vigne Vin., 42:79-87, 2008.

FRANCESCHI, V.R. \& HORNER, H.T. Calcium oxalate crystals in plants. Bot. Rev., 46:361-427, 1980.

FRIAS, I.; CALDEIRA, M.T.; PEREZ CASTINEIRA, J.R.; AVARRO AVINO, J.P.; CULIANEZ MACIA, F.A.; KUPPINGER, O.; STRANSKY, H.; PAGES, M.; HAGER, A. \& SERRANO, R. A major isoform of the maize plasma membrane $\mathrm{H}^{+}$-ATPase, characterization and induction by auxin in coleoptiles. Plant Cell, 8:1533-1544, 1996.

GUERRA, J.C.M.; SANTOS, G.A.; SILVA, L.S. \& CAMARGO, F.A.O. Macromoléculas e substâncias húmicas. In: SANTOS, G.A., ed. Fundamentos da matéria orgânica do solo: Ecossistemas tropicais \& subtropicais. 2.ed. Porto Alegre, Metrópole, 2008. p.19-26.

GUERRA, M.P.; DAL VESCO, L.L.; PESCADOR, R.; SCHUELTER, A.R. \& NODARI, R.O. Estabelecimento de um protocolo regenerativo para a micropropagação do abacaxizeiro. Pesq. Agropec. Bras., 34:1557-1563, 1999.

HAGER, A.; DEBUS, G.; EDEL, H.G.; STRANSKY, H. \& SERRANO, R. Auxin induces exocytosis and rapid synthesis of a high-turnover pool of plasma-membrane $\mathrm{H}^{+}$-ATPase. Planta, 185:527-537, 1991.
HISCOX, J.D. \& ISRAELSTAM, G.F. A method for the extraction of chlorophyll from leaf tissue without maceration. Can. J. Bot., 57:1332-1334, 1979.

HOAGLAND, D.R. \& ARNON, D.I. The water culture method of growing plants without soil. Berkeley, University of California, 1950. 32p.

INSTITUTO CAPIXABA DE PESQUISA, ASSISTÊNCIA TÉCNICA E EXTENSÃO RURAL - INCAPER. 'Vitória' nova cultivar de abacaxi resistente a fusariose. Vitória, 2006. (Documento, 148)

LARCHER, W. Ecofisiologia vegetal. São Carlos, Rima Artes e Textos, 2000. 531p.

LIU, C.H.; COOPER, R.J. \& BOWMAN, D.C. Humic acid application affects photosynthesis, root development, and nutrient content of creeping bentgrass. HortScience, 33:1023-1025, 1998.

MARQUES JUNIOR, R.; CANELLAS, L.P.; SILVA, L.G. \& OLIVARES, F.L. Promoção de enraizamento de microtoletes de cana-de-açúcar pelo uso conjunto de substâncias húmicas e bactérias diazotróficas endofíticas. R. Bras. Ci. Solo, 32:1121-1128, 2008.

MASCIANDARO, G.; CECCANTI, B. \& GARCIA, C. Soil agroecological management: Fertirrigation and vermicompost treatments. Biores. Technol., 59:199-206, 1999.

MELLO, M.R.F.; MARIANO, R.L.R.; MENEZES, M.; CÂMARA, T.R. \& ASSIS, S.M.P. Seleção de bactérias e métodos de bacterização de crescimento em mudas de abacaxizeiro micropropagadas. Summa Phytopathol., 28:222-228, 2002.

MOREIRA, M.A.; CARVALHO, J.G.; CHRYSTIANE, B.F \& PASQUAL, M. Resposta a adubação NPK de mudas micropropagadas de abacaxizeiro cv. Pérola em fase de aclimatação. Plant Cell Cult. Micropropag., 3:17-22, 2007.

MOREIRA, M.A. Produção e aclimatação de mudas micropropagadas de abacaxizeiro: Ananas comosus (L) Merrill cv. Pérola. Lavras, Universidade Federal de Lavras, 2001. 81p. (Tese de Doutorado)

MOREIRA, M.A.; CARVALHO, J.G.; PASQUAL, M.; FRÁGUAS, C.B. \& SILVA, A.B. Efeito de substratos na aclimatação de mudas micropropagadas de abacaxizeiro cv. Pérola. Ci. Agrotec., 30:875-879, 2006.

MURASHIGUE, T. \& SKOOG, F. A revised medium for rapid growth and bioassays with tobacco tissue culture. Physiol. Plant., 15:473-497, 1962.

MUSCOLO, A.; BOVALO, F.; GIONFRIDDO, F. \& NARDI, S Earthworm humic matter produces auxin-like effects on Daucus carota cell growth and nitrate metabolism. Soil Biol. Biochem., 31:1303-1311, 1999.

MUSCOLO, A. \& NARDI, S. Auxin or auxin-like activity of humic matter. In: DROZD, J.; GONET, S.S.; SENESI, N. $\&$ WEBER, J., eds. The role of humic substances in the ecosystems and environmental protection. Wroclaw, Polish Society of Humic Substances, 1997. p.987-992. 
NARDI, S.; CONCHERI, G. \& DELL'AGNOLA, G. Biological activity of humus. In: PICCOLO, A., ed. Humic substances in terrestrial ecosystems. New York, Elsevier, 1996. p.361406.

NARDI, S.; PIZZEGHELLO, D.; MUSCOLO, A. \& VIANELLO, A. Physiological effects of humic substances in higher plants. Soil Biol. \& Biochem., 34:1527-1537, 2002.

PICCOLO, A. The supramolecular structure of humic substances. Soil Sci., 166:810-832, 2001.

PROENÇA, S.L. \& SAJO, M.G. Anatomia foliar de bromélias ocorrentes em áreas de cerrado do Estado de São Paulo. Acta Bot. Bras., 21:657-673, 2007.

PURVIS, M.; COLLIER, D. \& WALLS, D. Laboratory techniques in botany. London, Butterworths, 1964.

PY, C. La piña tropical. Barcelona, Blume, 1969. 278p.

QUAGGIOTTI, S.; RUPERT, B.; PIZZEGHELLO, D.; FRANCIOSO, O.; TUGNOLI, V. \& NARDI, S. Effect of low molecular size humic substances on nitrate uptake and expression of genes involved in nitrate transport in maize (Zea mays L.). J. Exper. Bot., 55:803-813, 2004.

RAMOS, M.J.M.; MONNERAT, P.H.; CARVALHO, A.J.C.; PINTO, J.L.A. \& SILVA, J.A. Nutritional deficiency in 'Imperial' pineapple in the vegetative growth phase and leaf nutrient concentration. Acta Hortic., 702:133-139, 2006.

RODDA, M.R.C.; CANELLAS, L.P.; FACANHA, A.R.; ZANDONADI, D.B.; ALMEIDA, D.L.; GUERRA, J.G.M. \& SANTOS, G.A. Estímulo no crescimento e na hidrólise de ATP em raízes de alface tratadas com humatos de vermicomposto. I - Efeito da concentração R. Bras. Ci. Solo, 30:649-656, 2006.

SONDEGAARD, T.E.; SCHULZA, A. \& PALMGREN, M.G. Energization of transport processes in plants. Roles of plasma membrane $\mathrm{H}^{+}$-ATPase. Plant Physiol., 136:24752482,2004
SOUZA JÚNIOR, E.E.; BARBOZA, S. B.S. C. \& SOUZA, L.A.C. Efeitos de substratos e recipientes na aclimatação de plântulas de abacaxizeiro [Ananas comosus (L.) Merril] cv. Pérola. Pesq. Agropec. Trop., 31:147-151, 2001.

TEIXEIRA, J.B.; CRUZ, A.R.R.; FERREIRA, F.R. \& CABRAL, J.R. Biotecnologia aplicada à produção de mudas: Produção de mudas micropropagadas de abacaxi. Biotecnol. Ci. Desenvol., 3:42-47, 2001.

TEJADA, M. \& GONZALEZ, J.L. Effect of foliar application of a byproduct of the two-step olive oil mill process on rice yield. Eur. J. Agron., 21:31-40, 2004.

VAUGHAN, D. \& MALCOLM, R.E. Influence of humic substances on growth and physiological process. In: VAUGHAN, D. \& MALCOLM, R.E., eds. Soil organic matter and biological activity. Dordrecht, Kluwer Academic, 1985. p.37-75.

VISSER, S.A. Fluorescence phenomena of humic matter of aquatic origin and microbial cultures. In: CHRISTMAN, R.F. \& GESSING, E.T., eds. Aquatic and terretrial humic materials. Ann Arbor, Ann Arbor Science, 1983. p.183202.

WEBER， O.B.; CORREIA， D.; SILVEIRA， M.R.S.; CRISÓSTOMO, L.A.; OLIVEIRA, E.M. \& SÁ, E.G. Efeito da bactéria diazotrófica em mudas micropropagadas de abacaxizeiros Cayenne Champac em diferentes substratos Pesq. Agropec. Bras., 38:689-696, 2003.

WELLBURN, A.R. The spectral determination of chlorophylls $a$ and $b$, as well as total carotenoids, using various solvents with spectrophotometers of different resolution. J. Plant Physiol., 144:7-313, 1994.

ZANDONADI, D.B.; CANELLAS, L.P. \& FAÇANHA, A.R. Indolacetic and humic acids induce lateral root development through a concerted plasmalemma and tonoplast $\mathrm{H}^{+}$pumps activation. Planta, 225:1583-1595, 2007. 